\title{
Research Paper: Differential Effect of Amyloid Beta1-40 on Short-term and Long-term Plasticity in Dentate Gyrus of a Rat Model of Alzheimer Disease
}

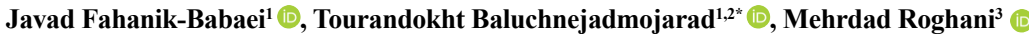 \\ 1. Physiology Research Center, Iran University of Medical Sciences, Tehran, Iran. \\ 2. Department of Physiology, School of Medicine, Iran University of Medical Sciences, Tehran, Iran. \\ 3. Neurophysiology Research Center, Shahed University, Tehran, Iran.
}

\begin{tabular}{|c|c|}
\hline $\begin{array}{l}\text { Use vour device to can } \\
\text { and read the article online }\end{array}$ & $\begin{array}{l}\text { Citation: Fahanik-Babaei, J., Baluchnejadmojarad, T., \& Roghani, M. Differential Effect of Amyloid Beta1-40 on Short-term } \\
\text { and Long-term Plasticity in Dentate Gyrus of a Rat Model of Alzheimer Disease. Basic and Clinical Neuroscience, 11(4), 517- } \\
\text { 524. http://dx.doi.org/10.32598/bcn.9.10.190 } \\
\text { doi http://dx.doi.org/10.32598/bcn.9.10.190 }\end{array}$ \\
\hline
\end{tabular}

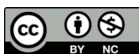

Article info:

Received: 26 May 2018

First Revision: 10 Jun 2018

Accepted: 24 Jul 2018

Available Online: 01 Jul 2020

Keywords:

Alzheimer disease, Amyloid beta, Synaptic plasticity

\begin{abstract}
A B S T RA C T
Introduction: Synaptic plasticity is inappropriately affected by neurodegenerative diseases, including Alzheimer Disease (AD). In this study, we examined the effect of intrahippocampal amyloid-beta (A $\beta 1-40)$ on dentate gyrus Long-term Potentiation (LTP) and presynaptic shortterm plasticity in a rat model of $\mathrm{AD}$.

Methods: The experimental groups in this research included the control with no treatment, sham-operated receiving the vehicle (normal saline), and A $\beta$-lesioned groups. For modeling $\mathrm{AD}$, aggregated $\mathrm{A} \beta 1-40(10 \mu \mathrm{g} / 2 \mu \mathrm{l}$ on each side) was injected into the hippocampal CA1. Three weeks later, Population Spike (PS) amplitude and slope ratios were determined at different Inter-pulse Intervals (IPI) of 10, 20,30, and $50 \mathrm{~ms}$ as a valid indicator of the shortterm presynaptic facilitation and/or depression. In addition, PS amplitude and slope were taken as an index of long-term synaptic plasticity after application of High-frequency Stimulation (HFS) to induce LTP in the medial perforant-dentate gyrus pathway.

Results: No significant differences were noted amongst the experimental groups regarding fEPSP slope and paired-pulse indices as indicators of short-term plasticity. In contrast, fEPSP slope and PS amplitude significantly decreased following the application of HFS in A $\beta$-injected group. In addition, there was no significant difference between the control and sham-operated groups regarding the mentioned parameters.

Conclusion: Findings of this study clearly demonstrated that microinjection of A $\beta 1-40$ into the CA1 could impair LTP in dentate gyrus but could not modify short-term plasticity.
\end{abstract}




\section{Highlights}

- $\mathrm{AD}$ is a neurodegenerative disease with high prevalance in the elderly.

- The main reason of $\mathrm{AD}$ is Brain extracellular deposition of Amyloid-Beta $(\mathrm{A} \beta)$ peptide plaques

- Two kinds of synaptic plasticity are Short-term Plasticity (STP) and Long-term Plasticity or Potentiation (LTP)

- According to experimental studies loss of cognitive performance in $\mathrm{AD}$ are somewhat due to alterations in presynaptic functions and disability of the synapse to act normally.

\section{Plain Language Summary}

Alzheimer Disease (AD) is a neurodegenerative disease in the elderly with high prevalance that finally leads to dementia and death. Amyloid-Beta $(A \beta)$ peptide plaques is the key pathologic hallmark of patients with AD. In experimental models it is reported that $\mathrm{A} \beta$ alone even before the development of plaques could cause neuronal injury and death in affected patients. Experimental studies indicate that loss of cognitive performance in $\mathrm{AD}$ are somewhat due to alterations in presynaptic functions and disability of the synapse to act normally. By progression of the disease, the number of synapses relative to neuronal population decreases, and this imbalance is associated with memory loss. This study was designed to examine the effect of intrahippocampal A $\beta 1-40$ on Dentate Gyrus (DG) LTP and presynaptic short-term plasticity in a rat model.

\section{Introduction}

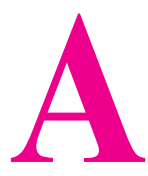

lzheimer Disease (AD) is a neurodegenerative disease in the elderly with high incidence in the human society that at its late stages, finally leads to dementia and death (Crous-Bou, Minguillon, Gramunt, \& Molinuevo, 2017; Lane, Hardy, \& Schott, 2018). Brain extracellular deposition of Amyloid-Beta $(A \beta)$ peptide plaques is the key pathologic hallmark of patients with AD (Magalingam, Radhakrishnan, Ping, \& Haleagrahara, 2018). $A \beta$ due to its neurotoxic properties is responsible for neuronal degeneration and synaptic loss in AD (Reiss, Arain, Stecker, Siegart, \& Kasselman, 2018; Vargas, Cerpa, Munoz, Zanlungo, \& Alvarez, 2018). Accumulating evidence in experimental models of AD and in affected patients strongly indicates that $A \beta$ alone even before the development of plaques could cause neuronal injury and death (Parihar \& Brewer, 2010). Synaptic plasticity is the capability of synaptic structures to alter the efficacy and/or strength of the synaptic transmission. In this respect, alterations in synaptic efficacy are suggested to play a key role in learning and memory processes (Esmaeili Tazangi, Moosavi, Shabani, \& Haghani, 2015).

Two kinds of synaptic plasticity have been introduced, i.e. Short-term Plasticity (STP) using paired-pulse stimulation protocol (Moghaddam, Baluchnejadmojarad, Roghani, Goshadrou, \& Ronaghi, 2013; Ohno et al.,
2011) at appropriate inter-stimulus intervals (ISIs) that reflects the probable release of the presynaptic neurons with a spontaneous decay of conductance level, and Long-term Plasticity or Potentiation (LTP) using a tetanic stimulation protocol (high-frequency stimulation, HFS) that is responsible for the memory formation in humans (Ohno et al., 2011). Regarding STP, it can occur as Paired-Pulse Facilitation (PPF) or Paired-Pulse Depression (PPD), and their generation in the hippocampus is strongly related to the location of stimulation, stimulus strength, and the time between the two successive stimuli (Ohno et al., 2011). PPF is due to inward calcium current through presynaptic structures (Nicoll \& Malenka, 1999; Staubli, 1992) and PPD is attributed to the desensitization of AMPA receptors in addition to modulation of the GABAergic system (Li, Vigh, \& von Gersdorff, 2007; Ohno-Shosaku et al., 2011; Unichenko, Myakhar, \& Kirischuk, 2012).

Experimental studies have demonstrated that loss of cognitive performance in $\mathrm{AD}$ are somewhat due to alterations in presynaptic functions and disability of the synapse to act normally (Fernandez-Fernandez, Rosenbrock, \& Kroker, 2015; Lee et al., 2012; Yang, Wang, Wang, Justice, \& Zheng, 2009). In moderate deterioration of cognitive ability, the number of active synapses in the hippocampus decreases with counterbalancing through increasing the dimension of synapses. Finally, with the progression of the disease, the number of syn- 
apses relative to neuronal population decreases, and this imbalance is associated with memory loss (Giralt et al., 2017; Kawano et al., 2017; Vilella et al., 2017). However, the detailed pathogenic mechanisms that are responsible for the occurrence of these changes are not well-defined. Hippocampal LTP is a well-defined kind of synaptic plasticity that its deficit could lead to memory decline (Babri et al., 2014; Freir, Costello, \& Herron, 2003). The effect of $\mathrm{A} \beta$ on short-term presynaptic facilitation and/ or depression has not been well identified. Considering different forms of $\mathrm{A} \beta$ (with varying degrees of neurotoxicity) and different sites of injection (i.e. intracerebral or intracerbroventricular), this study was designed to examine the effect of intrahippocampal $A \beta 1-40$ on Dentate Gyrus (DG) LTP and presynaptic short-term plasticity in a rat model of AD using HFS and paired pulse stimulation protocols.

\section{Materials and Methods}

\subsection{Animals}

Male albino Wistar rats were obtained from the laboratory animal breeding center of Iran University of Medical Sciences (IUMS), Tehran, Iran (age: 11-13 weeks; body weight: 250-290 g). The rats were housed in Plexiglas cages with woodchip bedding in groups of 3-4 per cage at standard room temperature $\left(21-23^{\circ} \mathrm{C}\right)$ and a humidity of $40-50 \%$ under $12 \mathrm{~h}$ light-dark cycle (the light period started on 07:00 a.m.). Food and water were freely provided. All practical interventions regarding animals and their care were done in compliance with guidelines stipulated by the National Institutes of Health of USA for the care and use of experimental animals and those of IUMS (Tehran, Iran).

\subsection{Materials}

\section{A $\beta 1-40$ was purchased from Sigma (USA).}

\subsection{A $\beta(1-40)$ preparation}

A $\beta 1-40$ was dissolved in normal saline at a concentration of $2 \mathrm{mg} / \mathrm{ml}$ and stored at $-20^{\circ} \mathrm{C}$. Aggregation of $\mathrm{A} \beta 1-40$ was done by in vitro incubation at $37^{\circ} \mathrm{C}$ for $72 \mathrm{~h}$.

\subsection{Experimental procedure}

The rats $(n=18)$ were randomly allocated and grouped into three experimental groups, including the control, sham, and A $\beta 1-40$ groups. The sham group received was injected with an equivalent volume of normal saline. On the day of surgery, animals ( $n=6$ per group) were anesthetized with an i.p. injection of ketamine- $\mathrm{HCl}$ (100 $\mathrm{mg} / \mathrm{kg})$ and xylazine $(10 \mathrm{mg} / \mathrm{kg})$. The rats were fixed in a stereotaxic apparatus and according to the Paxinos' brain atlas, the scalp was incised at midline and small burr holes were made at appropriate sites bilaterally (AP -3.8, ML $\pm 2.2, \mathrm{DV}-2.7$ ). Then, the A $\beta 1-40$ solution (10 $\mu \mathrm{g} / 2 \mu \mathrm{l})$ was bilaterally injected into the dorsal hippocampus over 5 min by a Hamilton microsyringe. Shamoperated rats received the vehicle solution. The skin was then sutured and the animals were maintained to recover in a warm box before returning to their home cages.

\subsection{Electrophysiological study}

Three weeks following intracerebral microinjection of $\mathrm{A} \beta$ or vehicle, rats were deeply anesthetized with urethane (1.7-1.8 g/kg b.w., i.p.) and their heads were placed in a stereotaxic frame. A homeothermic device was used to sustain body temperature at $36.5^{\circ} \mathrm{C}$. Then, the cranium was exposed and two burr holes were drilled for the insertion of stimulating and recording electrodes. Bipolar stainless steel stimulating electrode with a diameter of $0.125 \mathrm{~mm}$ (A-M Systems, USA) was placed in the medial perforant pathway (4.2 $\mathrm{mm}$ lateral to the lambda, 3.2 mm ventrally) and a stainless steel recording electrode was placed in the DG with the maximum response (3.8 $\mathrm{mm}$ posterior and $2.2 \mathrm{~mm}$ lateral to the bregma).

Evoked field potentials were recorded from DG cells after stimulation of the medial perforant pathway. Recording of field potentials began at least 15 min following the insertion of the stimulating and recording electrodes. Applied stimuli were biphasic square waves (a width of $200 \mathrm{~ms}$ ). Extracellular field potentials were amplified $1000 \mathrm{x}$, digitized at $10 \mathrm{kHz}$, and filtered at a band of $0.1 \mathrm{~Hz}-10 \mathrm{kHz}$ with the aid of a differential amplifier. Signals were passed through the A/D interface (Science Beam Co., Iran) to a computer, and data were analyzed using the e-probe software. Stimulation intensity was adjusted at a level to evoke $40 \%$ of the maximal response (field Excitatory Post-Synaptic Potential (fEPSP) and Population Spike (PS)). Also, PS amplitude was measured as the average of the potential difference between the peak of the first positive wave and the peak of the first negative deflection as well as the potential difference between the peak of the second positive wave and the peak of the first negative deflection. Meanwhile, the fEPSP slope, as an index of synaptic efficacy, was determined as the maximum slope between the initial point of fEPSP and the first positive wave. 


\subsubsection{Input/output functions}

Input-Output (I/O) functions were obtained by graded variation of the stimulus intensity $(100-1100 \mu \mathrm{A})$ for the assessment of synaptic efficacy before LTP induction. fEPSP and PS were triggered in DG using $0.1 \mathrm{~Hz}$ stimulation and five evoked responses were averaged at each current intensity.

\subsubsection{Paired-pulse response}

After recording for $40 \mathrm{~min}$, paired-pulse depression/facilitation was determined. The response to paired-pulse stimulation was subsequently recorded and delivered at $40 \%$ of maximal stimulus intensity with the Inter-Pulse Intervals (IPI) of 10, 20, 30, and $50 \mathrm{~ms}$. For each IPI, 10 consecutive evoked responses were averaged. The population spike amplitude ratio [ratio of the second population spike amplitude to the first population spike amplitude; PS2/PS1\%, Paired-Pulse Index (PPI)] and the fEPSP slope ratio [second fEPSP slope/first fEPSP slope (\%); fEPSP2/fEPSP $1 \%$ ] were determined at various inter-stimulus intervals.

\subsubsection{LTP}

After stable baseline recording for at least $30 \mathrm{~min}$, LTP was induced through the delivery of HFS (10 trains of 15 pulses at $200 \mathrm{~Hz}$ separated by $10 \mathrm{~s}$ ), and after the tetanic stimuli, the baseline stimulation was resumed and recording continued for at least $90 \mathrm{~min}$, and 5 consecutive evoked responses were averaged at stimulus intervals of $10 \mathrm{~s}$.

\subsection{Data analysis}

All results are shown as Means \pm SEM For electrophysiological comparison, data were analyzed using One-

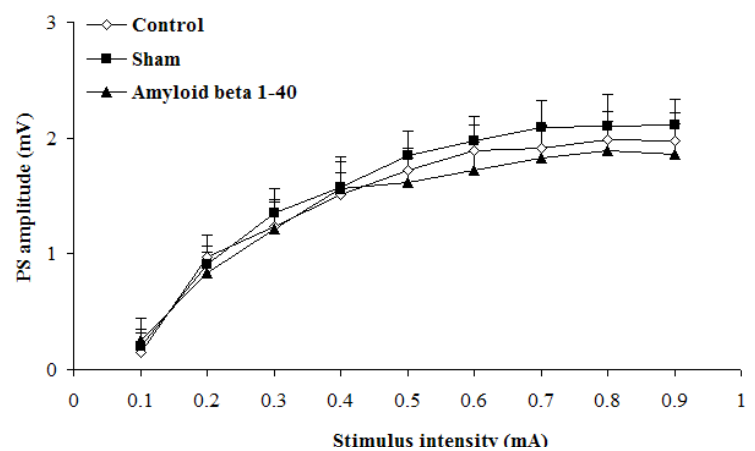

Way Analysis of Variance (ANOVA), one-way repeated measures ANOVA, and Tukey post-hoc test. In addition, a p-value of less than 0.05 was considered significant.

\section{Results}

\subsection{Input/output (I/O) functions}

Stimulus-response curves were obtained from the DG following the stimulation of the medial perforant pathway to assess the synaptic potency (Figure 1). In this respect, one-way repeated measures ANOVA showed that PS amplitude and fEPSP slope prior to application of paired-pulse stimulation and HFS protocols did not significantly differ between the groups $\left(\mathrm{F}_{2,14}=1.94, \mathrm{P}>0.05\right)$.

\subsection{Paired-pulse responses}

As shown in Figure 2, the paired-pulse protocols were applied to the medial perforant pathway, and recording was obtained from the DG at different IPIs of 10, 20, 30, and $50 \mathrm{~ms}$. One-way repeated measures ANOVA showed no significant differences regarding EPSP slope and paired-pulse indices amongst the experimental groups.

\subsection{LTP}

LTP responses were recorded from the DG of different groups (Figure 3). Statistical analysis of different time points before the application of HFS did not indicate a significant difference (baseline data for fEPSP slope and PS amplitude) among the groups. In other words, intrahippocampal bilateral microinjection of aggregated A 1 1-40 did not significantly affect baseline responses. In contrast, one-way repeated measures ANOVA indicated a significant difference amongst the groups for fEPSP slope $\left(\mathrm{F}_{2,15}=1.15 .3, \mathrm{P}<0.01\right)$ and PS amplitude

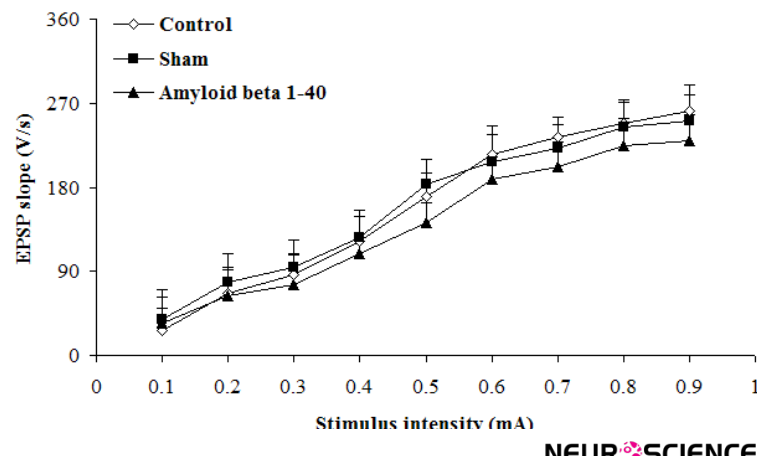

NEUR SCIENCE Figure 1. The input-output curves shown as field Excitatory Post-Synaptic Potential (fEPSP) slope and Population Spike (PS) amplitude in the dentate gyrus

Each point represents data obtained from 6 rats. Specimen recordings showed changes in baseline and LTP recordings 60 min after high-frequency stimulation HFS. Each recording is the average of 10 consecutive recordings at $100 \mathrm{~s}$ with an interval of 10 s. There was no statistically significant difference amongst the groups. 

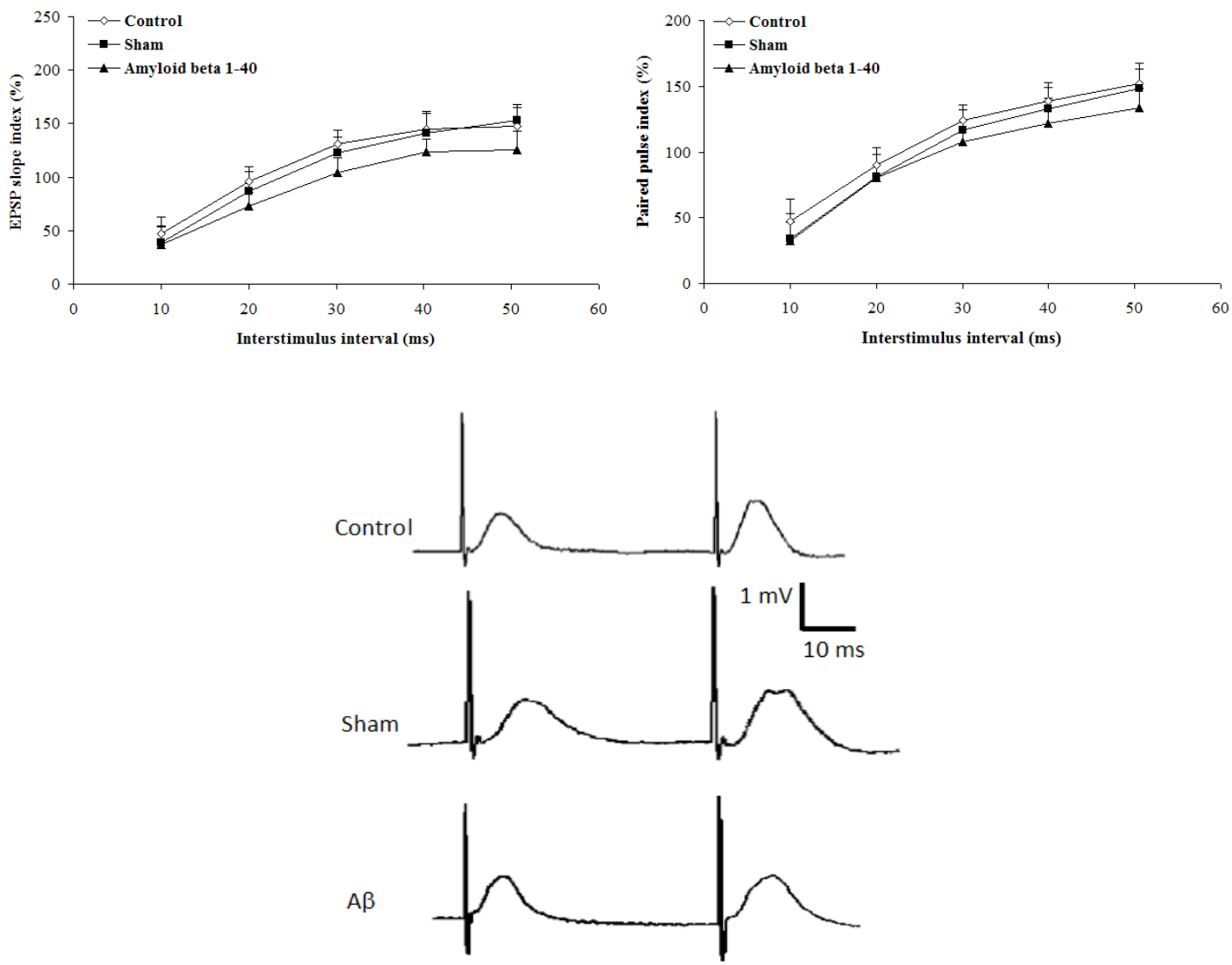

NEUR SCIENCE

Figure 2. The effect of Amyloid-Beta (A $\beta 1-40)$ on paired-pulse responses in the hippocampal dentate gyrus

At the intervals of 10, 20, 30, and 50, as shown by field Excitatory Post-Synaptic Potential (fEPSP) slope ratio (second response/ first response ratio) and Population Spike (PS) amplitude ratio (second response/first response ratio) ( $\mathrm{n}=6$ per group) and traces recorded at dentate gyrus at an inter-stimulus interval of $50 \mathrm{~ms}$. There was no statistically significant difference amongst the groups. Recording of the average of 10 consecutive PSs evoked by the paired stimuli in $100 \mathrm{~s}$.

$\left(\mathrm{F}_{2,15}=13.8, \mathrm{P}<0.01\right)$ following the application of HFS. In this respect, the fEPSP slope was significantly lower in the $A \beta 1-40$ group than the control group at all time points $\left(\mathrm{F}_{2,15}=11.7,13.9, \mathrm{P}<0.05-0.01\right)$. A similar significant difference was also found out for PS amplitude after the application of HFS amongst the groups $\left(\mathrm{F}_{2,15}=13.5, \mathrm{P}<0.01\right)$. In this regard, PS amplitude was depressed and was significantly lower in the $A \beta 1-40$ group compared with the control group at all time points $\left(\mathrm{F}_{2,15}=14.7, \mathrm{P}<0.01\right)$.

\section{Discussion}

The main objective of this study was to exactly determine the differential effect of the $A \beta 1-40$ on DG short-term and long-term plasticity in a rat model of $\mathrm{AD}$ through intracerebral microinjection of aggregated A $\beta 1-40$. Our findings demonstrated that long-term synaptic plasticity as LTP is severely impaired following the A $\beta 1-40$ injection with no significant changes in shortterm plasticity determined by a paired-pulse protocol.
In this respect, we observed that the intrahippocampal injection of A $\beta 1-40$ severely dampens fEPSP slope and PS amplitude following the LTP protocol. Our findings regarding suppression of LTP were in agreement with earlier reports, which have reported that the exposure to soluble oligomers of $\mathrm{A} \beta$ could lower neuronal excitability and related synaptic plasticity and LTP in the hippocampal regions, including DG (Wang et al., 2002). Such oligomers do not significantly affect Long-Term Depression (LTD) associated with memory processes (Wang et al., 2002). In this regard, $A \beta$ exposure could contribute to the pathogenesis of AD both by impairing LTP and memory formation at the cellular level and also by developing neuroplasticity imbalance in addition to the impaired capacity for neurons to recover (Wang et al., 2002). In contrast, Li et al. (2009) showed that the oligomers of $A \beta$ could positively affect hippocampal LTD via disrupting neuronal uptake of the glutamate neurotransmitter (Li et al., 2009). 

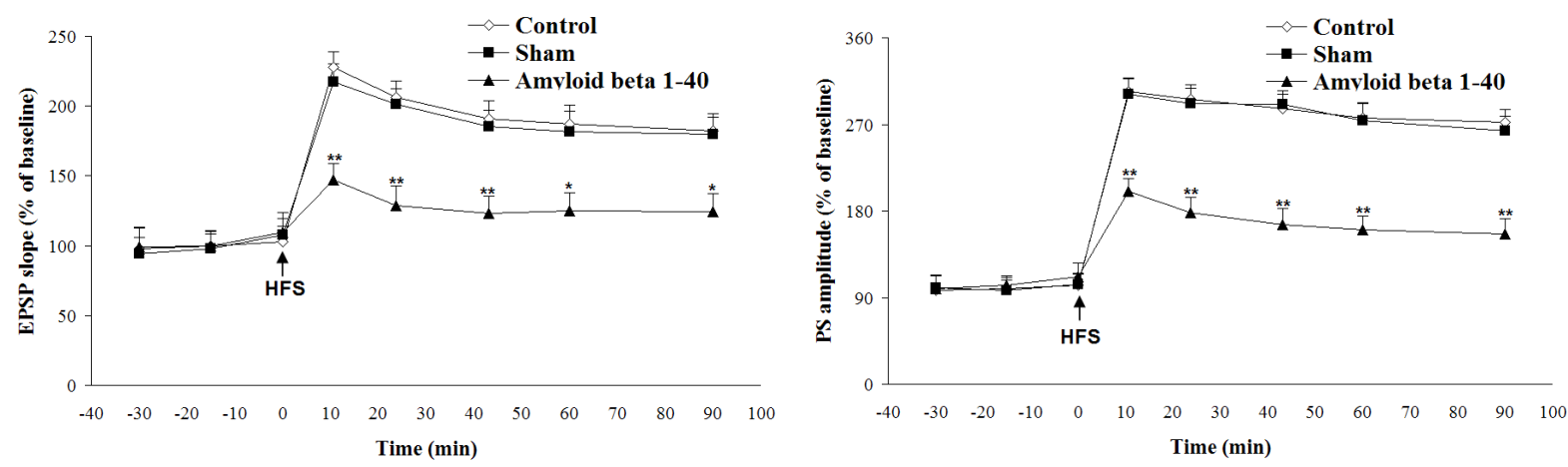

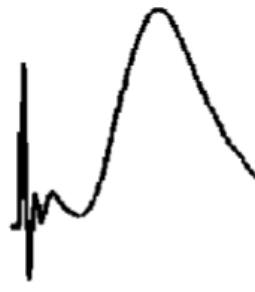

Control

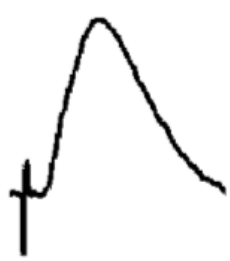

Sham

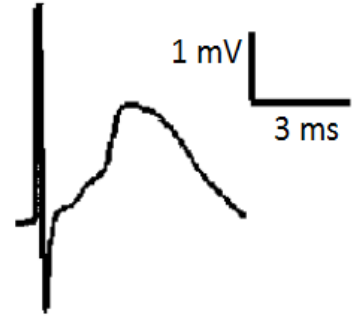

$A \beta$

NEUR:SCIENCE

Figure 3. The effect of amyloid-beta (A $\beta 1-40)$ on long-term potentiation (LTP) in the hippocampal dentate gyrus using HighFrequency Stimulation (HFS) as shown by field Excitatory Post-Synaptic Potential (fEPSP) slope and Population Spike (PS) amplitude and representative traces of evoked responses in the dentate gyrus of the rat hippocampus following stimulation of the medial perforant path; ( $\mathrm{n}=6$ per group); $\mathrm{P}<0.05$; and ${ }^{* *} \mathrm{P}<0.01$ versus the control group.

LTP is considered as a major synaptic mechanism that is valuable for the assessment of long-term synaptic plasticity in rats and mice. Post-tetanic LTP is postulated as a physiological form of synaptic plasticity and its appearance in cortical and subcortical regions is considered as a valuable tool for the assessment of learning and memory at the cellular and/or molecular levels (Bliss \& Collingridge, 1993). According to previous reports, LTP induction and maintenance are significantly disturbed after the application of tetanic stimulation in animal models of AD (Lambert et al., 1998; Walsh et al., 2002) that is also consistent with our findings. Mechanistically, LTP is greatly dependent on N-Methyl- d-aspartic acid or N-Methyl- DAspartate (NMDA) receptors and is a widely-accepted mechanism for the occurrence of synaptic plasticity via the presynaptic release of the glutamate and consequent depolarization of post-tsynaptic target due to the activation of NMDA receptors and ensuing inward calcium currents. The neurotoxic peptide $\mathrm{A} \beta$ could target glutamate receptors, by which it exerts its synaptotoxic effects. In this regard, $A \beta$ could decrease expression of NMDA receptors leading to a decrease in NMDA and $\alpha$-amino-3hydroxy-5-methyl-4-isoxazolepropionic acid (AMPA) receptor-mediated synaptic transmission through enhancing receptors endocytosis (Hsieh et al., 2006).
In addition, brain nicotinic acetylcholine receptors are strongly engaged in learning and memory process through inducing LTP (Drever, Riedel, \& Platt, 2011; Maurer \& Williams, 2017). Experimental studies have indicated that $\mathrm{A} \beta$ fragments could lead to cholinergic dysfunction and consequent cognitive decline in individuals with AD (Nordberg, 2001). A $\beta$ peptides could bind to some kinds of nicotinic receptors, which leads to the accumulation of intracellular $\mathrm{A} \beta$ and subsequent deficits in synaptic function (D'Andrea \& Nagele, 2006), finally resulting in reduced release of acetylcholine, as an excitatory neurotransmitter, and consequently negatively affecting LTP. Furthermore, A $\beta$ fragments could inhibit NMDA receptor-dependent synaptic neurotransmission partly through lowering inward calcium current via NMDA receptors, leading to a reduction in phosphorylation of calcium and calmodulin-dependent protein kinase II (CaMKII) followed by attenuation of the LTP process (Zhao, Watson, \& Xie, 2004). In this regard, Lisman et al. in 2002 showed that CaMKII molecules are strongly involved in the occurrence of LTP in the hippocampal DG (Lisman, Schulman, \& Cline, 2002).

In this research, we also assessed short-term plasticity in DG through the application of paired-pulse protocol. The paired-pulse ratio is correlated with the pre- 
synaptic release of neurotransmitters and is regarded as short-term plasticity (Fortune \& Rose, 2002; Zucker \& Regehr, 2002). Short-term plasticity is dependent on residual calcium in presynaptic terminals. An enhanced level of calcium following the application of the first stimulus could elevate the probability of neurotransmitter release as a result of the application of the second stimulus (Debanne, Guerineau, Gahwiler, \& Thompson, 1996). In addition, GABAergic inhibitory interneurons could affect the excitability of the hippocampal granular and pyramidal cells through feed-forward and feed-back circuits, in this way modulating short-term plasticity related to presynaptic regions (Jiang, Sun, Nedergaard, \& Kang, 2000). In our research, an A $\beta 1-40$ exposure did not significantly affect PS amplitude and fEPSP slope due to the application of paired-pulse stimulation protocols at IPIs of 10, 30, 40, and $50 \mathrm{~ms}$. Thus, it can be concluded that the reduction of PS amplitude and EPSP slope following HFS application is possibly unrelated to presynaptic function/activity and post-synaptic regions are affected to a greater degree following $\mathrm{A} \beta$ injection.

To conclude, our findings demonstrated that the longterm synaptic plasticity as LTP is severely impaired following $A \beta$ injection with no significant changes in short-term plasticity determined by the application of a paired-pulse protocol.

\section{Ethical Considerations}

\section{Compliance with ethical guidelines}

All ethical principles were considered in this article. The participants were informed about the purpose of the research and its implementation stages; they were also assured about the confidentiality of their information; Moreover, They were allowed to leave the study whenever they wish, and if desired, the results of the research would be available to them.

\section{Funding}

This study was part of a PhD. thesis of Javad FahanikBabaei in the Physiology Research Center, Iran University of Medical Sciences, Tehran (Grant No.: 93-03130-24998).

\section{Authors' contributions}

All authors contributed equally in preparing all parts of the research.

\section{Conflict of interest}

The authors declared no conflict of interest.

\section{References}

Babri, S., Mohaddes, G., Feizi, I., Mohammadnia, A., Niapour, A., \& Alihemmati, A., et al. (2014). Effect of troxerutin on synaptic plasticity of hippocampal dentate gyrus neurons in a betaamyloid model of Alzheimers disease: An electrophysiological study. European Journal of Pharmacology, 732, 19-25. [DOI:10.1016/j ejphar.2014.03.018] [PMID]

Bliss, T. V., \& Collingridge, G. L. (1993). A synaptic model of memory: Long-term potentiation in the hippocampus. Nature, 361(6407), 31-39. [DOI:10.1038/361031a0] [PMID]

Crous-Bou, M., Minguillón, C., Gramunt, N., \& Molinuevo, J L. (2017). Alzheimer's disease prevention: From risk factors to early intervention. Alzheimer's Research $\mathcal{E}$ Therapy, 9(1), 71 [DOI:10.1186/s13195-017-0297-z] [PMID] [PMCID]

D'Andrea, M. R., \& Nagele, R. G. (2006). Targeting the alpha 7 nicotinic acetylcholine receptor to reduce amyloid accumulation in Alzheimer's disease pyramidal neurons. Current pharmaceutical design, 12(6), 677-84. [DOI:10.2174/138161206775474224] [PMID]

Debanne, D., Guerineau, N. C., Gähwiler, B. H., \& Thompson, S. M (1996). Paired-pulse facilitation and depression at unitary synapses in rat hippocampus: Quantal fluctuation affects subsequent release. The Journal of Physiology, 491(1), 163-76. [DOI:10.1113/ jphysiol.1996.sp021204] [PMID] [PMCID]

Drever, B. D., Riedel, G., \& Platt, B. (2011). The cholinergic system and hippocampal plasticity. Behavioural Brain Research, 221(2), 50514. [DOI:10.1016/j.bbr.2010.11.037] [PMID]

Esmaeili Tazangi, P. E., Moosavi, S. M. S., Shabani, M., \& Haghani, M. (2015). Erythropoietin improves synaptic plasticity and memory deficits by decrease of the neurotransmitter release probability in the rat model of Alzheimer's disease. Pharmacology Biochemistry and Behavior, 130, 15-21. [DOI:10.1016/j.pbb.2014.12.011] [PMID]

Fernández-Fernández, D., Rosenbrock, H., \& Kroker, K. S. (2015). Inhibition of PDE2A, but not PDE9A, modulates presynaptic shortterm plasticity measured by paired-pulse facilitation in the CA1 region of the hippocampus. Synapse, 69(10), 484-96. [DOI:10.1002/ syn.21840] [PMID]

Fortune, E. S., \& Rose, G. J. (2002). Roles for short-term synaptic plasticity in behavior. Journal of Physiology-Paris, 96(5-6), 539-45. [DOI:10.1016/S0928-4257(03)00009-3]

Freir, D. B., Costello, D. A., \& Herron, C. E. (2003). A $\beta 25-35$-induced depression of long-term potentiation in area CA1 in vivo and in vitro is attenuated by verapamil. Journal of Neurophysiology, 89(6), 3061-9. [DOI:10.1152/jn.00992.2002] [PMID]

Giralt, A., Gómez-Climent, M. Á., Alcalá, R., Bretin, S., Bertrand, D., \& Delgado-García, J. M., et al. (2017). The AMPA receptor positive allosteric modulator S 47445 rescues in vivo CA3-CA1 long-term potentiation and structural synaptic changes in old mice. Neuropharmacology, 123, 395-409. [DOI:10.1016/j.neuropharm.2017.06.009] [PMID] 
Hsieh, H., Boehm, J., Sato, C., Iwatsubo, T., Tomita, T., Sisodia, S., \& Malinow, R. (2006). AMPAR removal underlies A $\beta$-induced synaptic depression and dendritic spine loss. Neuron, 52(5), 831-43. [DOI:10.1016/j.neuron.2006.10.035] [PMID] [PMCID]

Jiang, L., Sun, S., Nedergaard, M., \& Kang, J. (2000). Pairedpulse modulation at individual GABAergic synapses in rat hippocampus. The Journal of Physiology, 523(Pt 2), 425-39. [DOI:10.1111/j.1469-7793.2000.t01-1-00425.x] [PMID] [PMCID]

Kawano, H., Oyabu, K., Yamamoto, H., Eto, K., Adaniya, Y., \& Kubota, K., et al. (2017). Astrocytes with previous chronic exposure to amyloid $\beta$-peptide fragment 1-40 suppress excitatory synaptic transmission. Journal of Neurochemistry, 143(6), 624-34. [DOI:10.1111/jnc.14247] [PMID]

Lambert, M. P., Barlow, A. K., Chromy, B. A., Edwards, C., Freed, R., \& Liosatos, M.,et al. (1998). Diffusible, nonfibrillar ligands derived from Abeta1-42 are potent central nervous system neurotoxins. Proceedings of the National Academy of Sciences of the United States of America, 95(11), 6448-53. [DOI:10.1073/pnas.95.11.6448] [PMID] [PMCID]

Lane, C. A., Hardy, J., \& Schott, J. M. (2018). Alzheimer's disease. European Journal of Neurology, 25(1), 59-70. [DOI:10.1111/ene.13439] [PMID]

Lee, S. H., Kim, K. R., Ryu, S. Y., Son, S., Hong, H. S., \& Mook-Jung, I., et al. (2012). Impaired short-term plasticity in mossy fiber synapses caused by mitochondrial dysfunction of dentate granule cells is the earliest synaptic deficit in a mouse model of Alzheimer's disease. Journal of Neuroscience, 32(17), 5953-63. [DOI:10.1523/JNEUROSCI.0465-12.2012] [PMID] [PMCID]

Li, G. L., Vigh, J., \& von Gersdorff, H. (2007). Short-term depression at the reciprocal synapses between a retinal bipolar cell terminal and amacrine cells. Journal of Neuroscience, 27(28), 7377-85. [DOI:10.1523/JNEUROSCI.0410-07.2007] [PMID] [PMCID]

Li, S., Hong, S., Shepardson, N. E., Walsh, D. M., Shankar, G. M., \& Selkoe, D. (2009). Soluble oligomers of amyloid Beta protein facilitate hippocampal long-term depression by disrupting neuronal glutamate uptake. Neuron, 62(6), 788-01. [DOI:10.1016/j.neuron.2009.05.012] [PMID] [PMCID]

Lisman, J., Schulman, H., \& Cline, H. (2002). The molecular basis of CaMKII function in synaptic and behavioural memory. Nature Reviews Neuroscience, 3(3), 175-90. [DOI:10.1038/nrn753] [PMID]

Magalingam, K. B., Radhakrishnan, A., Ping, N. S., \& Haleagrahara, N. (2018). Current concepts of neurodegenerative mechanisms in Alzheimer's disease. BioMed Research International, 2018, 3740461. [DOI:10.1155/2018/3740461] [PMID] [PMCID]

Maurer, S. V., \& Williams, C. L. (2017). The cholinergic system modulates memory and hippocampal plasticity via its interactions with non-neuronal cells. Frontiers in Immunology, 8, 1489. [DOI:10.3389/ fimmu.2017.01489] [PMID] [PMCID]

Moghaddam, H. K., Baluchnejadmojarad, T., Roghani, M., Goshadrou, F., \& Ronaghi, A. (2013). Berberine chloride improved synaptic plasticity in STZ induced diabetic rats. Metabolic Brain Disease, 28(3), 421-8. [DOI:10.1007/s11011-013-9411-5] [PMID]

Nicoll, R. A., \& Malenka, R. C. (1999). Expression mechanisms underlying NMDA receptor-dependent long-term potentiation. Annals of the New York Academy of Sciences, 868, 515-25. [DOI:10.1111/j.1749-6632.1999.tb11320.x] [PMID]
Nordberg, A. (2001). Nicotinic receptor abnormalities of Alzheimer's disease: Therapeutic implications. Biological Psychiatry, 49(3), 20010. [DOI:10.1016/S0006-3223(00)01125-2]

Ohno-Shosaku, T., Sugawara, Y., Muranishi, C., Nagasawa, K., Kubono, K., \& Aoki, N., et al. (2011). Effects of clozapine and Ndesmethylclozapine on synaptic transmission at hippocampal inhibitory and excitatory synapses. Brain Research, 1421, 66-77. [DOI:10.1016/j.brainres.2011.08.073] [PMID]

Ohno, T., Hasegawa, T., Tsuruoka, T., Terabe, K., Gimzewski, J. K., \& Aono, M. (2011). Short-term plasticity and long-term potentiation mimicked in single inorganic synapses. Nature Materials, 10(8), 591-5. [DOI:10.1038/nmat3054] [PMID]

Parihar, M. S., \& Brewer, G. J. (2010). Amyloid-beta as a modulator of synaptic plasticity. Journal of Alzheimer's Disease, 22(3), 741-63. [DOI:10.3233/JAD-2010-101020] [PMID] [PMCID]

Reiss, A. B., Arain, H. A., Stecker, M. M., Siegart, N. M., \& Kasselman L. J. (2018). Amyloid toxicity in Alzheimer's disease. Reviews in the Neurosciences, 29(6), 613-27. [DOI:10.1515/revneuro-2017-0063] [PMID]

Staubli, U. (1992). A peculiar form of potentiation in mossy fiber synapses. Epilepsy research. Supplement, 7, 151-7. [PMID]

Unichenko, P., Myakhar, O., \& Kirischuk, S. (2012). Intracellular Na+ concentration influences short-term plasticity of glutamate transporter-mediated currents in neocortical astrocytes. Glia, 60(4), 60514. [DOI:10.1002/glia.22294] [PMID]

Vargas, L. M., Cerpa, W., Munoz, F. J., Zanlungo, S., \& Alvarez, A R. (2018). Amyloid-beta oligomers synaptotoxicity: The emerging role of EphA4/c-Abl signaling in Alzheimer's disease. Biochimica et Biophysica Acta, 1864(4 Pt A), 1148-59. [DOI:10.1016/j.bbadis.2018.01.023] [PMID]

Vilella, A., Belletti, D., Sauer, A. K., Hagmeyer, S., Sarowar, T., \& Masoni, M., et al. (2017). Reduced plaque size and inflammation in the APP23 mouse model for Alzheimer's disease after chronic application of polymeric nanoparticles for CNS targeted zinc delivery. Journal of Trace Elements in Medicine and Biology, 45, 210-21. [DOI:10.1016/j.jtemb.2017.12.006] [PMID]

Walsh, D. M., Klyubin, I., Fadeeva, J. V., Cullen, W. K., Anwyl, R., \& Wolfe, M. S., et al. (2002). Naturally secreted oligomers of amyloid $\beta$ protein potently inhibit hippocampal long-term potentiation in vivo. Nature, 416(6880), 535-9. [DOI:10.1038/416535a] [PMID]

Wang, H. W., Pasternak, J. F., Kuo, H., Ristic, H., Lambert, M. P., \& Chromy, B., et al. (2002). Soluble oligomers of $\beta$ amyloid (1-42) inhibit long-term potentiation but not long-term depression in rat dentate gyrus. Brain Research, 924(2), 133-40. [DOI:10.1016/S00068993(01)03058-X]

Yang, L., Wang, Z., Wang, B., Justice, N. J., \& Zheng, H. (2009). Amyloid precursor protein regulates Cav1.2 L-type calcium channel levels and function to influence GABAergic short-term plasticity. The Journal of Neuroscience, 29(50), 15660-8. [DOI:10.1523/JNEUROSCI.4104-09.2009] [PMID] [PMCID]

Zhao, D., Watson, J. B., \& Xie, C. W. (2004). Amyloid beta prevents activation of calcium/calmodulin-dependent protein kinase II and AMPA receptor phosphorylation during hippocampal long-term potentiation. Journal of Neurophysiology, 92(5), 2853-8. [DOI:10.1152/jn.00485.2004] [PMID]

Zucker, R. S., \& Regehr, W. G. (2002). Short-term synaptic plasticity. Annual Review of Physiology, 64(1), 355-405. [DOI:10.1146/annurev. physiol.64.092501.114547] [PMID] 